\title{
BAKHTIN E OS PROCESSOS DE DESENVOLVIMENTO HUMANO
}

\section{BAKHTIN AND THE PROCESSES OF HUMAN DEVELOPMENT}

\author{
Fabio Scorsolini-Comin ${ }^{1}$ \\ Manoel Antônio dos Santos ${ }^{2}$
}

Scorsolini-Comin F; Santos MA. Bakhtin e os processos de desenvolvimento humano: um diálogo de, no mínimo, duas vozes. Rev. Bras. Cresc. e Desenv. Hum. 2010; 20(3) 745-756.

\section{Resumo:}

A obra de Bakhtin tem sido apropriada não apenas pela Linguística, como também por diferentes áreas do conhecimento, como a Psicologia, a Educação e as Artes. Ao aproximarmos este autor do campo do desenvolvimento humano, podemos compreender de que modo o dialogismo e a polifonia podem ser evocados no diálogo com os contextos desenvolvimentais e com as práticas discursivas. Essa aproximação contribui para repensar o paradigma científico que contempla o desenvolvimento unicamente como uma sequência linear de estágios e aquisições maturacionais. Para além dessas considerações reducionistas, Bakhtin provoca o leitor para narrar o seu próprio desenvolvimento, que é sempre relacional, dialógico e posicionado.

Palavras-chave: dialogismo; polifonia; linguagem; desenvolvimento; Bakhtin.

\begin{abstract}
Bakhtin's work has been appropriated not only for linguistics but also for different areas of knowledge such as Psychology, Education and Arts. Approximating this author's work to the field of human development, it can be understood how dialogism and the Arts. In approaching this author's field of language and human development, we can understand how the dialogism and polyphony can be evoked in dialogue with developmental contexts and discursive practices. This approximation helps to rethink the scientific paradigm which views the development as a linear sequence of maturational stages and acquisitions. Beyond these reductionist considerations, Bakhtin provoques the reader to narrate their own development, which is always relational, dialogic and positioned.
\end{abstract}

Key words: dialogic; polyphony; language development; Bakhtin.

1 Psicólogo, Mestre. Professor do Departamento de Psicologia do Desenvolvimento, da Educação e do Trabalho da Universidade Federal do Triângulo Mineiro (UFTM). E-mail: scorsolini@psicologia.uftm.edu.br

2 Psicólogo, Mestre e Doutor. Professor Doutor do Departamento de Psicologia e Educação da Faculdade de Filosofia, Ciências e Letras de Ribeirão Preto da Universidade de São Paulo. Bolsista de Produtividade Científica em Pesquisa do CNPq, Nível 1D. E-mail: masantos@ffclrp.usp.br

Endereço para correspondência: Prof. Dr. Manoel Antônio dos Santos. Departamento de Psicologia e Educação da FFCLRP USP, Avenida Bandeirantes, 3900, Monte Alegre, Ribeirão Preto, SP, CEP: 14040-901, Telefone: (16) 36023645 


\section{INTRODUÇÃO}

Bakhtin e seus tempos, para iniciar o diálogo que este estudo pretende instaurar, julga-se fundamental justificar a escolha do título. Ao afirmar que, em qualquer diálogo, estão presentes, no mínimo, duas vozes, Bakhtin não se refere ao fato de que, para travarmos uma conversa, precisamos estar com (ou nos remetermos a) um outro, pelo menos ${ }^{1}$. O diálogo, longe de ser constituído por quantidades (de falantes, de ouvintes ou de observadores), ultrapassa tal consideração. O diálogo bakhtiniano contrapõe-se ao discurso monológico, sendo compreendido como ação entre interlocutores ${ }^{1}$. Mesmo no discurso interior, diferentes vozes são por nós atualizadas, de modo que não há um discurso único, isolado de um contexto e do qual não participem outras vozes, outros discursos e alteridades.

Uma voz não produz diálogo - o que nos leva à necessidade de um outro que produza conosco sentidos e formas de se compreender a experiência humana a partir da linguagem. Assim, uma primeira referência que deve ser desenvolvida em relação à concepção de diálogo em Bakhtin repousa na busca de sentido como ato de compreensão, que escapa a uma relação puramente lógica ou factual. É no embate entre as diferentes vozes que podemos propiciar a escrita de um novo texto, como o que será aqui apresentado ${ }^{2}$.

Neste estudo discutiremos alguns construtos axiais da obra de Bakhtin, cuja relevância tem sido consistentemente reconhecida nas últimas décadas. A importância crescente atribuída a este autor pode ser estimada pelo modo reiterado como sua obra tem sido apropriada não apenas pela Linguística, como também por diferentes áreas do conhecimento, como a Psicologia, as Ciências Sociais, a Comunicação, a Educação e as Artes. Pretendemos colocar em relevo as potencialidades criadas ao aproximarmos essa obra do campo do desenvolvimento humano, o que permite compreender de que modo o dialogismo e a polifonia podem ser evocados no diálogo com os contextos desenvolvimentais e com as práticas discursivas. Ao desenvolvermos nossa argumentação, procuraremos explicitar de que modo, com o pensamento de Bakhtin, podemos revisar os paradigmas consagrados que informam a Psicologia do Desenvolvimento, fundamentando uma concepção alternativa que convoque o pesquisador a narrar seu próprio processo a partir de uma perspectiva dialógica que contemple as diferentes vozes, entoações e visões de mundo.

Mikhail Bakhtin nasceu em 1895, em Oriol, Rússia, e morreu em 1975, em Moscou. Como referido por Todorov, em prefácio escrito para a obra Estética da Criação Verbal ${ }^{1}$, esse autor marcou época como uma das figuras mais importantes do universo intelectual do século XX, sendo considerado por seus pares um grande pensador e teórico da língua. Articulador original, inaugurou uma renovação no campo dos estudos linguísticos e literários do Ocidente, depois que suas ideias ultrapassaram as fronteiras da Rússia, a partir da década de 1970.

Bakhtin foi um linguista na atualmente extinta União Soviética, onde viveu e desenvolveu sua obra em um contexto histórico marcado por intensas transformações sociopolíticas. No contexto e circunstância em que viveu, o marxismo exerceu acentuada influência em seu pensamento. Compartilhou com os teóricos marxistas um interesse pelo mundo histórico e social, especialmente pelo modo como os seres humanos pensam e agem sob condições concretas e objetivas de existência. $\mathrm{Ou}$ seja, seu interesse centrava-se na língua como forma por meio da qual as ideologias se articulam e mascaram a percepção da realidade. Para este autor, a língua é portadora de ideologias e uma prática material.

Bakhtin enfatizou a heterogeneidade concreta da parole, ou seja, a complexidade multiforme das manifestações de linguagem em 
situações sociais concretas, diferentemente de Saussure e dos estruturalistas, que privilegiaram a langue, isto é, o sistema abstrato da língua, com suas características formas passíveis de serem repetidas ${ }^{3}$. Bakhtin empreendeu uma crítica aos formalistas, no sentido de que, para ele, a doutrina formalista seria uma estética do material, reduzindo os problemas da criação poética a questões de linguagem. $\mathrm{O}$ fundamento de sua crítica reside na desnaturalização e caminha contra a reificação da "linguagem poética" e do estudo exaustivo de todos os processos por parte dos formalistas, que acabaram por menosprezar os demais ingredientes do ato de criação, como o conteúdo, a relação com o mundo e a forma.

Mais ainda, Bakhtin propunha examinar a língua além daqueles olhares, pois tinha o interesse de examinar como os povos a usavam. Entendia a língua como uma prática material e sempre constituída na interação social. Assim, enfatizava a necessidade de se pensar a palavra como resultante não apenas de processos físicos, mas também fisiológicos e psicológicos e, sobretudo, inserido nos interstícios das relações sociais.

Como homem de seu tempo, este autor enfrentou problemas com o regime totalitário soviético, que o levaram a se exilar e a elaborar muitos de seus trabalhos durante o exílio. Em razão de seus conflitos políticos com o regime que governava a União Soviética com mão de ferro, assim como das dificuldades de tradução de suas obras do russo para outros idiomas, as culturas ocidentais começaram a ter acesso aos seus textos tardiamente, somente a partir de $1970^{4}$.

\section{BAKHTIN EM LINHAS GERAIS}

As ideias de Bakhtin focalizam, primeiramente, o conceito de diálogo e a noção de que a língua é sempre um diálogo. Para este pensador, o verdadeiro objeto de estudo da Lin- guística seria o caminho pelo qual a realidade social partilhada pelos indivíduos torna-se condição essencial para que a língua se una à fala e se torne processo de comunicação capaz de produzir atos de fala.

A verdadeira substância da língua seria $o$ ato dialógico em seu acontecimento concreto, sendo que qualquer diálogo, além de ser ele próprio histórica e socialmente determinado, evidencia uma outra história: a história da própria linguagem. A língua seria o produto do trabalho coletivo e ininterrupto de sujeitos socialmente organizados, cujo processo instaura a construção, também coletiva, de conhecimentos, práticas e saberes sobre o mundo ${ }^{4,5}$.

Na concepção bakhtiniana, a noção central da pesquisa estética não deve ser a material, e sim a arquitetônica - ou a construção ou, ainda, a estrutura da obra - entendida como um ponto de encontro e interação entre material, forma e conteúdo ${ }^{6}$. O pensamento plural de Bakhtin possui uma unidade assegurada pela centralidade da linguagem, cujo método de análise é a dialética ${ }^{7}$. Na multiplicidade de temas investigados em sua obra - a sátira menipeia, a cultura popular medieval, o romance moderno ou escritores como Rabelais e Dostoievski - é possível identificar uma questão de base denominada dialogismo, conceito que será abordado ao longo deste artigo.

\section{EM BUSCA DE UM DIÁLOGO COM O DESENVOLVIMENTO HUMANO}

Primeiramente, deve-se destacar que Bakhtin é um teórico que parte da Linguística e que não apresenta propriamente uma teoria sobre desenvolvimento. No entanto, tem sido eminentemente evocado no sentido de subsidiar investigações nos domínios de diferentes ciências, entre elas a Psicologia, bem como a Educação. Estabelecendo uma aproximação com a Psicologia do Desenvolvimento, devese pontuar que Vigotski e Bakhtin, para citar- 
mos apenas um dos diálogos possíveis nessa interface, viveram na mesma época e apresentaram significativas convergências em suas obras, embora nenhum deles tenha se valido do outro na construção de suas teorias em torno da linguagem e do desenvolvimento humano. Eles possuíam não apenas formações diferentes, como também focos diferentes de investigação. Vigotski focalizou a sua obra muito mais nas questões desenvolvimentais, enquanto que Bakhtin estudou mais a linguagem a partir da perspectiva da Linguística, o que gerou mudanças importantes no modo como a linguagem era focalizada e concebida na ciência ${ }^{2,8}$.

Atravessando os campos da Psicologia e também da Educação, a obra de Vigotski é mais difundida, juntamente com a de Jean Piaget, e está ao alcance da maior parte dos pesquisadores e educadores. No caso da obra de Bakhtin, relativamente menos conhecida, essa situação vem sendo modificada nos últimos anos, ainda que as questões relativas à sua tradução do russo ainda sejam alvo de embates e discordâncias. Ainda assim, alguns pesquisadores $^{2}$ têm trabalhado com os pontos de intersecção entre esses pensadores. Um exemplo disso é o fato de ambos terem desenvolvido uma visão totalizante, não-fragmentada da realidade, compreendendo o homem como um conjunto de relações sociais. Desse modo, o homem não pode mais ser estudado, na Psicologia do Desenvolvimento Humano, como ser isolado, sob a perspectiva de uma postura individualizante que não olha para além de uma constituição física, como no caso de crianças com deficiência incluídas na escola ${ }^{4}$. A tônica não deveria ser colocada, portanto, nas capacidades ou incapacidades da criança em termos de rendimento escolar, mas no modo como ela, naquele ambiente, pode se desenvolver e oferecer a oportunidade inequívoca de que as pessoas do seu entorno (pais, professores, profissionais e coetâneos) também se desenvolvam e se transformem.

Alguns estudos, nesse sentido, fazem uso dos pressupostos bakhtinianos para se pensar o desenvolvimento humano em contextos diversos, como a adoção e as práticas de acolhimento, as identidades de pessoas envolvidas com o crime ${ }^{9}$, a inclusão de crianças na esco$1 \mathrm{a}^{4}$, o desenvolvimento de bebês em espaços coletivos $^{10}$, bem como a própria construção de um referencial teórico-metodológico na Psicologia do Desenvolvimento ${ }^{11,12}$. Nesse sentido, uma das noções mais evocadas nessas investigações é a de dialogismo.

O dialogismo é um conceito que permeia toda a obra de Bakhtin. Tal conceito pode ser definido como o princípio constitutivo da linguagem, o que significa que toda linguagem, em qualquer campo, está impregnada por relações dialógicas ${ }^{7}$. A concepção dialógica contém a ideia da relatividade da autoria individual e, por conseguinte, o destaque do caráter coletivo e social da produção de discursos.

De acordo com as proposições bakhtinianas, a alteridade marcaria o ser humano. Nessa vertente, o dialogismo seria o confronto das entoações e dos sistemas de valores, que possibilitam as mais variadas visões de mundo acerca de um tópico específico. $\mathrm{O}$ ser humano seria considerado um intertexto, na medida que não existe isoladamente, já que a sua vida se tece, entrecruza-se e interpenetrase com a experiência do outro. Os enunciados de um falante estão, sempre e inevitavelmente, atravessados pelas palavras do outro: o discurso elaborado pelo falante constitui e se constitui também do discurso do outro que o atravessa, condicionando o discurso do "eu".

$\mathrm{O}$ conceito de dialogismo assume importância capital á medida que entende a palavra como portadora de um constante dinamismo e o ser humano como agente, isto é, ele não apenas é influenciado pelo meio, como também age ativamente sobre o mesmo, transformando-o ${ }^{7}$. Além disso, do ponto de vista da comu- 
nicação, o dialogismo ratifica o conceito de comunicação como interação verbal e não-verbal, não meramente como transmissão da informação. O dialogismo operaria dentro de qualquer produção cultural, seja letrada ou analfabeta, verbal ou não verbal, elitista ou popular.

Em Bakhtin, a noção de dialógico ou de dialogicidade ${ }^{10}$ aparece por meio de diversas vertentes, a saber:

(a) Dialogismo interno da palavra: no discurso, o objeto está mergulhado em valores, crenças, descrições e definições, o que faz com que o falante se depare com múltiplos caminhos e vozes, que se tecem ao redor desse objeto - a dialética do objeto está ligada ao diálogo social que o engloba ${ }^{10}$;

(b) Dialogicidade nos enunciados: mesmo antes da concretização de um determinado enunciado - e também posteriormente, há outros enunciados, que emanam dos outros, aos quais o próprio enunciado está vinculado por algum tipo de relação. Nesse sentido, o próprio locutor seria um respondente, visto que ele não detém o ponto zero do discurso, ou seja, não o enunciou pela primeira vez, dado que o discurso não se origina nele. Assim, quando escolhemos uma palavra, costumamos extraíla de outros enunciados, fundamentamo-nos neles ou polemizamos com eles, os refutamos ou os confirmamos, os completamos ou os supomos conhecidos, baseamo-nos neles ou contamos com eles ${ }^{10}$. Essa seleção de palavras pode ser expressa, por exemplo, nas práticas educativas em ambientes educacionais distintos. Por meio das palavras selecionadas para descrever uma determinada realidade (contexto da inclusão) ${ }^{4}$ e também das palavras não selecionadas (tentando despistar a identificação das deficiências), as pessoas acabam expressando em seus comportamentos muitas de suas concepções acerca do desenvolvimento, da inclusão e da educação infantil. É nesse sentido que podemos compreender que o dialogismo não se expressaria apenas por meio das palavras faladas ou escritas, mas também naquelas subentendidas em nossa comunicação verbal ou não-verbal;

(c) Dialogismo construído pela emergência de várias vozes relacionadas a um tema específico, dadas pela antecipação da resposta dos outros e das possíveis respostas imaginadas por ele, em função do interlocutor e do contexto $^{10}$. Ainda seguindo o exemplo mencionado anteriormente, os modos como os pais e as professoras se posicionam frente à deficiência e à inclusão acabam sendo regulados por meio das expectativas que criam em torno do olhar do pesquisador. Sendo assim, o que cada indivíduo diz, o que expressa e o modo como atua nesse contexto devem ser balizados pelo que ele compreende que é mais adequado do ponto de vista psicológico ou pedagógico. Assim, as práticas empregadas com as crianças ditas "especiais" ou "deficientes" são orientadas pelos discursos presentes em cursos de formação para a inclusão, pelo olhar que apregoa a cidadania e o direito de todos à educação de qualidade, bem como pela presença do pesquisador no ambiente educacional ${ }^{4,13}$.

(d) Dialogização das linguagens: uma língua nacional é plural, pois abriga um compósito de linguagens: oriundas das reuniões sociais, familiar, cotidiana, sociopolítica; linguagem dos jargões profissionais (advogado, médico, empresário, político, professor...), linguagem de geração e de idade, linguagem de autoridade, linguagens ordinárias do dia; linguagem oratória, publicitária, científica, jornalística, literária..., com múltiplas vozes que estabelecem uma variedade de conexões e inter-relacionamentos ${ }^{10}$.

Desse modo, Bakhtin considera que o discurso é vivo e que vive nos modos sociais, devendo ser visto de formas contraditórias e como mundos de múltiplas linguagens que se interligam. Assim, essas diferentes linguagens ${ }^{10}$ não se excluem umas às outras, mas dialogicamente intersectam-se de maneiras muito diferentes, com uma interanimação em 
uma variedade de formas. Nesse processo, ocorre a coexistência de contradições socioideológicas entre o presente e o passado; entre diferentes épocas do passado; entre diferentes grupos socioideológicos do presente; entre tendências, escolas, círculos e assim por diante, com o encontro e a disputa entre pontos de vista sociolinguísticos distintos. Estes podem estar justapostos, mutuamente suplementando ou contradizendo-se; algumas linguagens falham a se desenvolverem, algumas morrem, enquanto que outras florescem em linguagens autênticas. Dado o jogo vivo, a linguagem se encontra em um histórico e ininterrupto processo de tornar-se, formando socialmente novas linguagens (p. 17).

A linguagem, como um dos aspectos mais relacionados ao desenvolvimento humano, pode ser compreendida, em Bakhtin, como relacionada aos contextos que constituem as pessoas. A linguagem como uma relação acaba por se descolar das tradições focadas em seus aspectos morfológicos. Desse modo, a ênfase não é dada ao que é adquirido em cada etapa do desenvolvimento, como destacava Piaget ${ }^{14}$, mas sim ao que é transformado, coconstruído, reinterpretado a partir da linguagem em seu acontecimento concreto, em sua apropriação como signo, em dado momento histórico-cultural, como compartilhado por Vigotski2,15. Em Bakhtin, o "sujeito" emerge na relação com o outro. É um sujeito dialógico e seu conhecimento é fundamentado no discurso que ele produz. O sujeito dialógico bakhtiniano é solidário das alteridades de seu discurso ao ser concebido em uma partição de vozes concorrentes, posto que a palavra do outro se transforma, dialogicamente, tendo um caráter criativo ${ }^{2}$. Tal sujeito é incompleto, não está acabado, mas mantém uma busca eterna de completude que se apresenta como inconclusiva, de tal modo que se torna impossível uma formação individual sem alteridade, pois o outro delimita e constrói o espaço de atuação do sujeito no mundo. No entanto, o outro constitui o sujeito ideologicamente e proporciona-lhe o acabamento ${ }^{3}$.

Sob a ótica da antropologia, o pensamento bakhtiniano permite uma compreensão radical da alteridade, pois apresenta uma visão multirreferenciada, na qual tempo e espaço estão em constante interação no processo de construção eu/outro 9 . Assim, é possível entender o outro de uma maneira original, pois ele é referido não como alguém que está fora de mim, que é estranho a mim, mas como alguém que me constitui, que contribui para o processo de construção de um eu que não me pertence integralmente e que somente existe a partir do olhar do outro. Assim, eu e outro se constroem mutuamente a partir de referenciais temporais e espaciais que os antecedem, são seus contemporâneos e, ao mesmo tempo, são seus herdeiros, no bojo de um processo no qual há múltiplas possibilidades de vir a ser ${ }^{8}$. Essa consideração está fortemente presente em perspectivas desenvolvimentais como as da Rede de Significações ${ }^{10,11,16}$ que, para além de uma compreensão de desenvolvimento como sinônimo de crescimento e de superação de fases e períodos evolutivos, compreende tal processo como dialógico, aberto a releituras e sempre atento aos sentidos e às relações que se colocam em cada momento. O que as pessoas são ou o que virão a ser não depende de uma sucessão de desenvolvimentos, mas um continuum de rupturas, apropriações e transformações que se dão à medida que nos desenvolvemos e interagimos com nossos múltiplos outros, evocados em nossa linguagem, em nosso pensamento e em nossos comportamentos, ações e práticas.

\section{NOSSA LÍNGUA BAKHTINIANA}

Como processo constituinte do desenvolvimento, a linguagem é compreendida para além de seus aspectos técnicos, morfológicos e sintáticos. Antes, é apreendida como um indicador de desenvolvimento, estando presente 
não apenas no nível verbal, mas também operando no não-verbal. Assim, Bakhtin destaca a centralidade da linguagem na vida do homem ${ }^{1}$. Em sua concepção, a palavra é o material da linguagem interior e da consciência, além de ser elemento privilegiado da comunicação na vida cotidiana, que acompanha toda criação ideológica, estando presente em todos os atos de compreensão e interpretação. Para este autor, a palavra tem sempre um sentido ideológico ou vivencial, relaciona-se totalmente com o contexto e carrega um conjunto de significados que lhe foram socialmente outorgados, negociados, negados e/ou assumidos. A palavra é também polissêmica e plural, uma presença viva da história, por conter múltiplos fios ideológicos que a tecem.

O produto do ato da fala, a enunciação, é de natureza social, sendo determinada pela situação mais imediata ou pelo meio social mais amplo. O que torna possível a compreensão de uma palavra é também aquilo que é presumido pelo ouvinte, porque toda palavra usada na fala real possui um acento de valor ou apreciativo, transmitido por meio da entoação expressiva. Por isso, juntamente com a palavra acontecem os gestos, as expressões faciais, a tonalidade e as entonações.

As concepções de Bakhtin exigem do leitor um olhar múltiplo sobre o mundo e sobre o outro. Trata-se de um olhar que vê o mundo a partir de ruídos, vozes, sentidos ${ }^{8}$, sons e linguagens que se misturam, (re)constroem-se, modificam-se e transformam-se continuamente ${ }^{17-20}$. Nesse cenário compreensivo, a palavra assume papel primordial, pois é a partir dela que o sujeito constitui e é constituído. A palavra não seria apenas um meio de comunicação, mas também conteúdo da própria atividade psíquica.

Essa visão dialógica supera a descrição dos elementos estritamente linguísticos e busca incluir também os elementos extralinguísticos que, direta ou indiretamente, condicionam a interação nos planos social, eco- nômico, histórico e ideológico. Em Bakhtin, toda produção cultural só pode existir no interior da linguagem.

Assim, tanto a linguagem como a história constituem pontos nodais na compreensão das questões humanas e sociais. Por ser polissêmica e dialógica, a palavra traz marcas culturais, sociais e históricas - marcas estas que estão cravadas em nosso desenvolvimento psíquico, motor e emocional. Nesse aspecto, Bakhtin estabelece o maior divisor de águas na construção de sua noção sobre a língua, pois, ao afirmar que o contexto histórico é parte constitutiva da linguagem, ele questiona as concepções estruturalistas que tomam a palavra como parte de um sistema abstrato de formas, em que o falante não tem poder de intervenção. $\mathrm{O}$ contexto histórico transforma a palavra fria do dicionário em fios dialógicos vivos, que refletem e refratam a realidade que a produziu ${ }^{17-20}$.

Por meio da linguagem, são colocadas em evidência as divergências, a materialização da luta de classes, a disputa pelo poder por grupos antagônicos, as crenças religiosas e as demonstrações de preconceitos. Nesse jogo - da palavra que se liga a uma outra palavra - o sujeito falante, que apreende o discurso do outro, não é um ser mudo e passivo. Ao contrário, é um ser perpassado pelas suas próprias palavras e pelas de outrem.

As palavras refletem e refratam, não de modo mecânico, os conflitos, e apontam as marcas ideológicas distintas de cada sujeito em interação. Nas palavras de Bakhtin ${ }^{19}$ : da mesma maneira que, se nós perdemos de vista a significação da palavra, perdemos a própria palavra, que fica, assim, reduzida à sua realidade física, acompanhada do processo fisiológico de sua produção. O que faz da palavra uma palavra é a sua significação (p. 49).

Nessa visão bakhtiniana não existem pensamento e linguagem como atributos humanos inatos, em uma perspectiva que se distancia das tradicionais concepções de lingua- 
gem como atributo exclusivamente biológico e como faculdade mensurável. A atividade mental do sujeito pertence totalmente ao campo social (nesse sentido, ao outro), pois a palavra e o material semiótico, externo aos sujeitos, são elementos determinantes para a organização do pensamento que, posteriormente, retornam ao campo social.

A palavra, em sua condição de signo, é adquirida no meio social e, uma vez interiorizada pelo sujeito, retorna ao meio social por meio dos processos interacionais, em uma forma diferenciada, o que aproxima Bakhtin das concepções de Vigotski ${ }^{2}, 15$. Ou seja, ela é dialeticamente alterada devido às colorações ideológicas que marcam as condições de produção. O sentido da palavra é totalmente determinado por seu(s) contexto(s), mas esses contextos não se encontram justapostos simplesmente, mas em uma situação de interação e de conflito tenso e ininterrupto ${ }^{17}$.

A palavra permite a constituição do sujeito $n a$ e por meio $d a$ linguagem. Não se trata aqui de lidar com uma palavra enquanto unidade da língua, nem com a significação dessa palavra, mas com o enunciado acabado e com um sentido concreto, ou seja, seu conteúdo. A significação da palavra se refere à realidade efetiva nas condições reais da comunicação verbal. A significação de uma palavra só pode ser entendida a partir dos enunciados, da sua entonação, que vai lhe conferir toda uma expressividade própria. A entonação expressiva não pertence à palavra, mas ao enunciado.

Para Bakhtin, a palavra deve ser considerada como um signo social, funcionando como elemento essencial que acompanha e comenta todo ato ideológico ${ }^{20}$ : os processos de compreensão de todos os fenômenos ideológicos (um quadro, uma peça musical, um ritual ou um comportamento humano) não podem operar sem a participação do discurso interior. Todas as manifestações da criação ideológica - todos os signos não-verbais - banham- se no discurso e não podem ser nem totalmente isoladas nem totalmente separadas dele (p. 38).

Como apontado anteriormente, a utilização da palavra na comunicação verbal ativa é sempre marcada pela individualidade e pelo contexto de produção. A palavra do outro e a palavra minha (impregnada por minha expressividade) possuem uma expressividade que não pertence à própria palavra, mas que nasce no contato entre a palavra e a realidade efetiva, nas circunstâncias de uma situação real, que se atualiza por meio de um enunciado individual ${ }^{1}$.

Ao destacar o caráter social da palavra, Bakhtin fez referência ao fato de que o desenvolvimento também não se dá ao acaso e de modo individual, como veiculado pelas teorias desenvolvimentais clássicas. Pelo contrário, a linguagem e o desenvolvimento se dão na interação social, no contato da pessoa com seus outros e o meio no qual vivem, sendo a palavra uma expressão possível dessa relação pessoa-cultura.

Assim, a palavra pode se apresentar como um "aglomerado de enunciados" " (p. 313). Estes enunciados estarão se organizando e se reorganizando de acordo com a época, o meio social, a família, as condições de desenvolvimento e a sociedade na qual o sujeito está inserido. Nas palavras de Bakhtin ${ }^{1}$, toda época, em cada uma das esferas da vida e da realidade, tem tradições acatadas que se expressam e se preservam sob o invólucro das palavras, das obras, dos enunciados, das locuções, etc. (p. 313).

É especialmente importante acentuar que a experiência verbal individual do homem evolui na interação contínua e permanente com os enunciados individuais dos outros. Toda fala está intimamente vinculada ao seu receptor, aos outros que também constituem o falante, na dialética dinâmica da vida humana. Os outros, para os quais o pensamento do sujeito se torna real, não são ouvintes passivos, mas participantes ativos da comunicação verbal, já que 
toda enunciação é elaborada para ir ao encontro de uma resposta desse(s) outros(s), em um processo reflexivo.

Nossa fala, isto é, nossos enunciados (que incluem as obras literárias), estão repletos de palavras dos outros, caracterizadas, em graus variáveis, pela alteridade ou pela assimilação, caracterizadas, também em grau variáveis, por um emprego consciente e decalcado. As palavras dos outros introduzem sua própria expressividade, seu tom valorativo, que assimilamos, reestruturamos, modificamos ${ }^{l}$ (p. 314).

Analisando a fundo a questão dos enunciados, Bakhtin afirma que em todo enunciado, dadas as condições concretas da comunicação verbal, pode-se perceber as palavras do outro ocultas ou semiocultas ${ }^{1}$. O enunciado se coloca como um fenômeno complexo, se analisado em sua relação dialógica entre o autor (locutor) e os outros enunciados. Os enunciados conhecem-se uns aos outros, ou seja, são dotados de um caráter recíproco, posto também que estão repletos de ecos e lembranças de outros enunciados, aos quais estão vinculados no interior de uma esfera comum da comunicação verbal.

$\mathrm{O}$ enunciado se coloca como uma resposta a enunciados anteriores dentro de uma dada esfera, refutando, confirmando, completando, baseando-se nestes outros enunciados que também o constituem. Todo enunciado remete a outro, em uma cadeia de sentido e de comunicação que está presente na linguagem.

Não apenas a linguagem verbal é relevante e portadora de significação ${ }^{19}$. Todo gesto ou processo do organismo, como a respiração, a circulação sanguínea, os movimentos do corpo, a articulação, o discurso interior, a mímica, a reação aos estímulos exteriores, enfim, "tudo o que ocorre no organismo pode tornar-se material para a expressão da atividade psíquica, posto que tudo pode adquirir um valor semiótico, tudo pode tornar-se expressivo" (p. 52).

A palavra acaba por se revelar, no momento de sua expressão, como o produto da interação viva das forças sociais, do mesmo modo que os gestos e o comportamento não verbal serão também o produto dessa interação. A enunciação também é produto da interação social, quer se trate de um ato de fala determinado pela situação imediata ou pelo contexto mais amplo que constitui o conjunto das condições de vida de uma determinada comunidade linguística. Em Para uma filosofia do ato, Bakhtin ${ }^{21}$ critica a cisão que se estabelece entre o conteúdo ou o sentido de um dado ato-atividade, e a realidade histórica do seu ser, a sua real e única experiência. Propõe que se pense a palavra ou o ato como possuindo um contexto histórico e, além disso, uma experiência concreta, no aqui e agora das situações. "A palavra está sempre carregada de um conteúdo ou de um sentido ideológico ou vivencial" ${ }^{19}$ (p. 95).

O ser humano só poderia ser compreendido no cerne dessa duplicidade conteúdo/realidade histórica, como parte de um todo, e não como objeto desmembrável e examinado separadamente, em dicotomias que acabam por colocar em um segundo plano o caráter dialógico deste ser inserido e interpenetrado pela história e pelos outros.

Na visão bakhtiniana, toda "expressão" comportaria tanto o seu conteúdo interior quanto a sua objetivação exterior para outrem (ou também para si mesmo). Todo o ato expressivo mover-se-ia entre as duas facetas, ou seja, entre o conteúdo interior e a objetivação exterior; toda palavra ou ato constituiria o produto da interação do locutor e do ouvinte - ou, em outras palavras, de um em relação a um outro. Extrapolando as considerações em torno da palavra e concebendo o elemento social das proposições bakhtinianas, o desenvolvimento também se daria nesse movimento, no relacionamento recíproco de um eu para um outro e deste outro para o eu, em um processo dinâmico. Nessa interação, cada pessoa, com suas características conflitantes, traria uma voz independente. Essas vozes diferentes e simultâ- 
neas implicam na concepção de sua coexistência e na possibilidade do diálogo entre elas, em que se abre a perspectiva de descontinuidade, diante da multiplicidade de vozes divergentes ${ }^{22,23}$.

\section{SOB O SIGNO DA MATERIALIDADE}

Em seu livro Marxismo e filosofia da linguagem, Bakhtin sugere que o signo ocupa um papel de destaque ${ }^{20}$. É nesse trabalho que o autor desenvolve a noção de que o domínio do signo é o mesmo domínio do ideológico. $\mathrm{O}$ universo dos signos seria um universo particular, pois o signo não existe apenas como parte de uma realidade, mas reflete e refrata uma outra realidade. Cada signo não é apenas um reflexo ou sombra da realidade, mas também um fragmento material dessa realidade.

Todo fenômeno que funciona como um signo possui uma encarnação material, como um som, uma massa física, uma cor, um movimento do corpo. Nas palavras de Bakhtin ${ }^{20}: U m$ signo é um fenômeno do mundo exterior. $O$ próprio signo e todos os seus efeitos (todas as ações, reações e novos signos que ele gera no meio social circundante) aparecem na experiência exterior (p. 33). Portanto, o signo possuiria uma realidade objetiva, passível de ser submetida a um estudo de caráter objetivo.

Para que se compreenda um signo é necessário que haja uma aproximação entre o signo aprendido e outros signos previamente conhecidos, ou seja, a compreensão só pode operar de um signo por meio de outros. Esta cadeia formada a partir de um signo para e por outro signo é única e contínua, e, em nenhum momento, pode ser quebrada sem que seja precedida pela corporificação do signo. Pode-se dizer que a realidade determina o signo e que o signo reflete e refrata a realidade em transformação.

O ser humano se reflete no signo, mas também se refrata no mesmo, no confronto dos interesses sociais, em uma comunidade semiótica. O signo possui uma dinâmica interna que se revela no exterior, nos conflitos, nas crises, na fala, no discurso, nas práticas, nos gestos $^{4,10,13}$. Está encarnado, vivo e em constante transformação, reflexão e refração.

Os signos emergem do processo de interação social (o signo se cria entre indivíduos, no meio social), tendo uma materialidade social - $\mathrm{o}$ gesto significante, a palavra, a imagem, são considerados signos que se materializam nos corpos, que se encarnam na fala, na expressão, enfim, em uma realidade material objetiva.

A existência do signo é a materialização dos fenômenos ideológicos juntamente com as condições e as formas da comunicação social. Nesse sentido, a palavra é vista por Bakhtin como um fenômeno ideológico por excelência, já que a realidade de toda palavra é absorvida por sua função de signo. "A palavra é o modo mais puro e sensível da relação social ${ }^{20 "}$ " (p. 36). A palavra ocupa uma posição de signo social.

Todo signo cultural compreendido e dotado de sentido torna-se parte de uma unidade da consciência verbalmente construída, em que toda palavra está presente em todos os atos de interpretação. O signo, como algo cravado no ser humano, possui uma realidade não apenas objetiva, mas corporificada, em que dinamiza, problematiza e tenciona o humano em sua ebulição de significados.

Desta maneira, ao aproximar Bakhtin do campo do desenvolvimento humano, fica evidente a desconstrução que ele promove na própria definição do que é desenvolvimento. Embora não tenha se debruçado sobre esse delineamento teórico, o autor avança no sentido de compreendê-lo como uma realidade dinâmica e aberta a diversas reconstruções.

Ao pensar a linguagem a despeito de seus elementos fonológicos, morfológicos e sintáticos, passando pela expressividade e pela materialização do signo, Bakhtin provoca uma ruptura na noção de desenvolvimento sequenciado e disposto em períodos. Além disso, sustenta que 
as mudanças se dão em termos dos contextos que favorecem ou não o desenvolvimento e dentro de determinações culturais que consideram a linguagem como um campo de embate, como um espaço no qual os saberes, concepções e práticas podem ser dispostos e entrar em diálogo, promovendo o desenvolvimento de pessoas e comunidades. Assim, o desenvolvimento não é limitado pelas condições históricas e culturais do indivíduo, mas um elemento que dialoga constantemente com essa realidade, adequandose ao papel, negando-se ou afirmando-se, o que conduz à reflexão sobre a ideia de desenvolvimento não necessariamente ligada à melhoria, mas sim à transformação.

Retomando o exemplo mencionado anteriormente, ao examinar o desenvolvimento de crianças expostas a processos de inclusão, precisamos manter o olhar atento para as transformações que vão se processando gradualmente, nas quais os protagonistas podem ser posicionados de maneiras distintas conforme a situação. Essa concepção nos leva a considerar o desenvolvimento como um processo dialógico, que se apresenta sempre em relação a um outro, que oferece à criança a oportunidade de mudança. Sendo assim, as práticas, os saberes e os demais elementos interativos podem ser recuperados pelas pessoas no aqui-eagora, modificando-se a depender dos movimentos produzidos, assumidos ou negados pelos profissionais, pais e crianças que protagonizam esse cenário.

Assim como no embate da palavra com o meio social, o desenvolvimento dar-se-ia em um processo tenso, de sucessivas aproximações e distanciamentos entre a pessoa e o meio, e não em termos de critérios etários ou de padrões e capacidades esperadas para cada período evolutivo. Na perspectiva dialógica de desenvolvimento, há espaço para interação, confronto e também para a convivência entre visões díspares de mundo. Ao assumirmos esse posicionamento, questionamos os conceitos de evolução, sequência, períodos e fases, em uma busca por elementos desenvolvimentais que expliquem o dinamismo das relações intersubjetivas, sustentando a visão dialógica do desenvolver-se (a si mesmo e ao outro).

Para Bakhtin, a realidade é essencialmente contraditória e em permanente transformação. Nesse sentido, propõe uma dialética que, nascendo do diálogo, nele se prolonga, colocando pessoas e textos em um permanente processo dialógico ${ }^{2}$. Seu pensamento coloca-se de modo sempre aberto, resistindo à ideia de acabamento e perfeição, o que pode ser estendido aos sentidos sobre desenvolvimento implícitos em sua obra.

Desse modo, podemos afirmar que Bakhtin concebe o desenvolvimento humano, tal como apregoa em relação à linguagem, como uma malha de discursos circulantes e plurais (discursos cujos sentidos não podemos controlar), em contraposição a um discurso monológico, que não apenas relativiza os posicionamentos, mas subsidia saberes e práticas em nosso meio que possuem uma materialidade e concretude que lhe são próprias. Ao desconstruir a noção de sequências desenvolvimentais ou fases de desenvolvimento quando pensa a linguagem, Bakhtin rompe com a ideia de maturação das estruturas orgânicas e promove uma compreensão não apenas mais ampla desse processo, como também mais alinhada aos paradigmas contemporâneos de ciência e produção do conhecimento ${ }^{16}$. Por conseguinte, ao abordar a centralidade da linguagem na vida humana acaba por endossar uma noção de desenvolvimento que extrapola um "passo a passo" metodológico, ao apregoar a não-cristalização das práticas. Nesse posicionamento, abre espaço para os movimentos de transformação inerentes à linguagem, à comunicação como domínio de expressão coletiva e ao próprio desenvolvimento como processo ininterrupto.

Agradecimento: à Prof. Dra. Katia de Souza Amorim, pela formação científica provida a Fábio Scorsolini-Comim, no período de 2004 a 2006. 


\section{REFERÊNCIAS}

1. Bakhtin M (Volochinov). Estética da criação verbal. Trad. Maria Ermantina Galvão G. Pereira. São Paulo: Martins Fontes; 1997.

2. Freitas MTA. Nos textos de Bakhtin e Vigotski: um encontro possível. In: Brait $\mathrm{B}$, org. Bakhtin, dialogismo e construção do sentido. $2^{\mathrm{a}}$ ed. Campinas: Editora da Unicamp; 2005: 295-314.

3. Marques MCS. Bakhtin: apontamentos temáticos. Primeira versão. 2004; 3(161): 2-7.

4. Scorsolini-Comin F, Amorim KS. "Em meu gesto existe o teu gesto": corporeidade na inclusão de crianças deficientes. Psicologia: Reflexão e Crítica. 2010; 23(2): 261-269.

5. Levitan D, Furtado JR, Zanella AV. Jovens, imagens de si e a cidade: discursos em movimento. Revista Brasileira de Crescimento e Desenvolvimento Humano. 2009; 19(2): 283-296.

6. Todorov T. (1979). Prefácio. In: Bakhtin M. Estética da criação verbal. São Paulo: Martins Fontes; 1992.

7. Lukianchuki C. Dialogismo: a linguagem verbal como exercício do social. Revista Sinergia. 2001; 2(2).

8. Scorsolini-Comin F, Santos MA. Poesia mediada: dialogismo, linguagem e comunicação no filme "O carteiro e o poeta". Revista Eletrônica de Comunicação, 2007; 4: $1-15$.

9. Soares-Silva AP. (Des)continuidades no envolvimento com o crime: construção de identidade narrativa de ex-infratores. São Paulo: IBCCRIM; 2003.

10. Amorim KS. Concretização de discursos e práticas histórico-culturais, em situações de frequência de bebês em creche. Tese de Doutorado em Saúde Mental, Faculdade de Medicina de Ribeirão Preto, Universidade de São Paulo; 2002.

11. Rossetti-Ferreira MC, Amorim KS, Soares-Silva AP, Carvalho AMA. Desafios metodológicos na perspectiva da rede de significações. Cadernos de Pesquisa, 38(133): 147-170; 2008.
12. Rossetti-Ferreira MC, Amorim KS, Silva APS. Uma perspectiva teórico-metodológica para análise do desenvolvimento humano e do processo de investigação. Psicologia: Reflexão e Crítica, 13(2): 281-293; 2000.

13. Yaszlle CHD. Pré-escolas convivendo com a paralisia cerebral: uma análise do processo de inclusão/exclusão. Dissertação de Mestrado, Faculdade de Medicina de Ribeirão Preto, Universidade de São Paulo, Ribeirão Preto; 2001.

14. Valsiner J. One hundred years: a constructive jubilee celebration for Lev Vygotsky and Jean Piaget. Culture \& Psychology, 2: 243-245; 1996.

15. Vigotski LS. Pensamento e Linguagem. São Paulo: Martins Fontes; 1987.

16. Rossetti-Ferreira MC, Amorim KS, Silva APS, Carvalho AMA, orgs. Rede de significações e o estudo do desenvolvimento. São Paulo: Artmed; 2004.

17. Barros DLP. Dialogismo, polifonia e enunciação. In: Fiorin JL, org. Dialogismo, polifonia, intertextualidade: em torno de Bakhtin. São Paulo: Edusp; 1994.

18. Barbosa MV. A concepção de palavra em Bakhtin. Primeira versão. 2002; 20.

19. Bakhtin M (Volochinov). Marxismo e filosofia da linguagem. $7^{\mathrm{a}}$ ed. Trad. Michel Lahud e Yara Frateschi Vieira. São Paulo: Hucitec; 1995.

20. Bakhtin M (Volochinov). Marxismo e filosofia da linguagem. $9^{\mathrm{a}}$ ed. Trad. Michel Lahud e Yara Frateschi Vieira. São Paulo: Hucitec; 1999.

21. Bakhtin M. Toward a philosophy of the act. Trad. Ed Vadim Liapunov, Michael Holquist. Texas: University of Texas Press; 1993.

22. Santos MA, Gomes WB. Self dialógico: teoria e pesquisa. Psicologia em Estudo, 15(2): 353-361; 2010.

23. Hermans HJM. The construction and reconstruction of a dialogical self. Journal of Constructivist Psychology, 16: 89-130; 2003.

Recebido em 08/09/2010 Modificado em: 15/10/2010 Aceito em 29/10/2010 